\title{
Modeled and observed soil moisture variability over a region of Argentina
}

\author{
Lorena Ferreira, ${ }^{1}$ * Héctor Salgado, ${ }^{2}$ Celeste Saulo ${ }^{3,4}$ and Estela Collini ${ }^{1,2}$ \\ I Servicio Meteorológico Nacional, Buenos Aires, Argentina \\ ${ }^{2}$ Servicio de Hidrografía Naval, Buenos Aires, Argentina \\ ${ }^{3}$ Departamento de Ciencias de la Atmósfera y los Océanos, Universidad de Buenos Aires, Buenos Aires, Argentina \\ ${ }^{4}$ Centro de Investigaciones del Mar y la Atmósfera, UBA-CONICET, Buenos Aires, Argentina
}

* Correspondence to:

L. Ferreira, Senvicio Meteorológico

Nacional, 25 de Mayo 658

(Cl002AVN), Ciudad Autónoma

de Buenos Aires, Argentina.

E-mail: ferreira@smn.gov.ar

Received: 2 August 2010

Revised: 14 March 201 I

Accepted: 25 March 2011

\begin{abstract}
The aim of this study is to document how soil moisture variability is represented by global analyses and regional atmospheric models compared with a unique dataset of sparse measurements over an agricultural productive area of Argentina. Results show that normalized simulated soil moisture values and their temporal variability are largely different from the observations. However, there is a strong agreement among values derived using the same land surface model, suggesting a strong influence of the forcing fields used by the different analyses/simulations. This work also discusses possible sources of model limitations for representing soil moisture variability over the region. Copyright $\left({ }^{\circ} 2011\right.$ Royal Meteorological Society
\end{abstract}

Keywords: land surface models; soil moisture variability; South America

\section{Introduction}

The terrestrial surface acts as a source and/or sink of atmospheric enthalpy and moisture by means of sensible and latent heat fluxes, regulating the feedback cycles of the climatic system. Surface states can be described through several variables (e.g. temperature and soil moisture) and parameters (e.g. albedo, soil type, land use). In particular, soil moisture modulates the energy partition at the land-atmosphere interface, playing an important role in the hydrological cycle and affecting temporal scales that goes from daily to seasonal (Viterbo, 2001). Increasing efforts are devoted to understand processes related to soil moisture variability, and how soil moisture affects predictability at short-to-medium ranges and even longer time scales (see Betts 2009 for a review). While over the American Continent most of these studies are focused on North America, there are a few that concentrate on South America (Collini et al., 2008; Grimm et al., 2007; Saulo et al., 2010; Xue et al., 2006, among others). A general statement found in many of these works is that the atmospheric circulation and precipitation are sensitive to soil moisture conditions. However, the lack of soil moisture and other soil parameter's data sets prevents from drawing conclusive results from available works. As clearly stated by Stensrud (2007), 'there is precious little information on what is occurring below the ground surface'. And this aspect becomes even more critical over areas like South America, where soil measurements are scarce. In Gevaerd and Freitas (2006a) and Gevaerd et al. (2006b), estimations of soil-water content derived from land surface models (LSMs) are compared with observed data in northern
Brazil. Their work shows that simulated and observed soil moisture behave in a similar way and they have also emphasized that an improvement in the soil moisture initial condition can lead to a better representation of meteorological conditions.

The results of a field campaign encompassing 21 dates including volumetric soil moisture observations, sparsely distributed over two consecutive years and representative of a small agricultural productive area in central Buenos Aires province, were recently reported by Salgado (2009). Given the importance that accurate soil moisture representation may have on weather forecasts quality, the aim of this study is to explore the relationship between available soil moisture data sets obtained from the GDAS (Global Data Assimilation System), GLDAS (Global Land Data Assimilation System, Rodell et al., 2004), and from Weather Research and Forecasting-Advanced Research Weather (WRF-ARW) (Skamarock et al., 2005) short-range forecasts, and a set of observations obtained during a field campaign developed within one of the most productive regions of the Argentinean Pampean flatlands. It should be considered that the most valid comparison among these data sets is through their variability and not through their absolute amounts. This is because soil moisture derived from models should be interpreted as an index that measures the state of soil wetness according to that particular model and not as variables that can be isolated (and compared) without considering further details. The reader is referred to Koster et al. (2009) for a profound discussion about this issue. In order to better understand the observed/model soil moisture variability, we also examine its relationship with precipitation. 


\section{Data and methodology}

Between 2006 and 2007, a field campaign to measure surface soil moisture, vegetation cover, leaf area index (LAI), and canopy height among others variables was carried out (Salgado, 2009). The sampling region corresponds to the centre of Buenos Aires Province - Argentina, located around $37^{\circ} 07^{\prime} \mathrm{S}$ and $59^{\circ} 41^{\prime} \mathrm{W}$, as indicated in Figure 1 . The corresponding dates are indicated on the $x$-axis of Figure 3.

The soil samples at $0-15$ and $15-30 \mathrm{~cm}$ were extracted using a soil drill and afterwards processed with the gravimetric method. This procedure was applied at 22 sites distributed inside the area under study and these measurements were taken between $0900 \mathrm{~h}$ and noon local time, corresponding to 12 and 15 UTC, respectively. The mean value from these 22 sites is considered as representative of the area, while the standard deviation corresponding to these observations is used as a measure of variability around this mean value.

For the same dates, GLDAS runs with NOAH LSM (National Centers for Environmental Prediction/Oregon State University/Air Force/Hydrologic Research Lab Model) and GDAS soil moisture data for the first two layers $(0-10$ and $10-40 \mathrm{~cm}$, which roughly correspond to the observations) were obtained. The horizontal grid spacing of these data sets is $0.25^{\circ}$ and $1^{\circ}$, respectively.

GLDAS is a global land data assimilation system based on alternative LSMs (NOAH has been selected for this study) forced by GDAS analysis, radiation fluxes derived using method no. 39 of the Air Force Weather Agency's Agricultural Meteorology modeling system, and precipitation fields from the NOAA Climate Prediction Center's operational global 2.5 5-day Merged Analysis of Precipitation (CMAP). In turn, GDAS assimilates a variety of conventional data and satellite-derived observations, and produces operational, global analyses for four synoptic hours, based on the NCEP Global Forecast System, which also uses NOAH LSM (http://www.emc.ncep.noaa.gov/gc_wmb/documentat ion.html).

In order to evaluate soil moisture representation during campaign dates, a WRF-ARW model with similar configuration to that used operationally at the Research Center for the Sea and the Atmosphere (Saulo et al., 2008) was adopted to obtain 24-27 h forecasts. Current WRF model settings include microphysics scheme (Hong and Lim, 2006), convection parameterization (Kain, 2004), the Rapid Radiative Transfer Model (Mlawer et al., 1997) and Dudhia scheme (Dudhia, 1989) to represent radiative fluxes and the Yon-Sei boundary layer scheme (Hong and Pan, 1996). As GLDAS and GDAS, the WRF model also used the same version of NOAH LSM (Chen and Dudhia, 2001). Land use and land cover categories were generated by US Geological Survey (Anderson et al., 1976).

The model was run in non-hydrostatic mode, with $20 \mathrm{~km}$ horizontal resolution and boundary conditions derived from the GDAS analysis. The WRF-ARW performance over the same region but run in forecast mode and with $40 \mathrm{~km}$ horizontal grid spacing was discussed by Ruiz et al. (2010).

For this work, the WRF-ARW model was initialized at $12 \mathrm{UTC}$ and run for $27 \mathrm{~h}$ periods, in order to obtain fields comparable with the observations taken between 12 and 15 UTC. Measured and simulated values are analyzed using the model grid point closest to the geographical location of the observations, indicated in Figure 1.

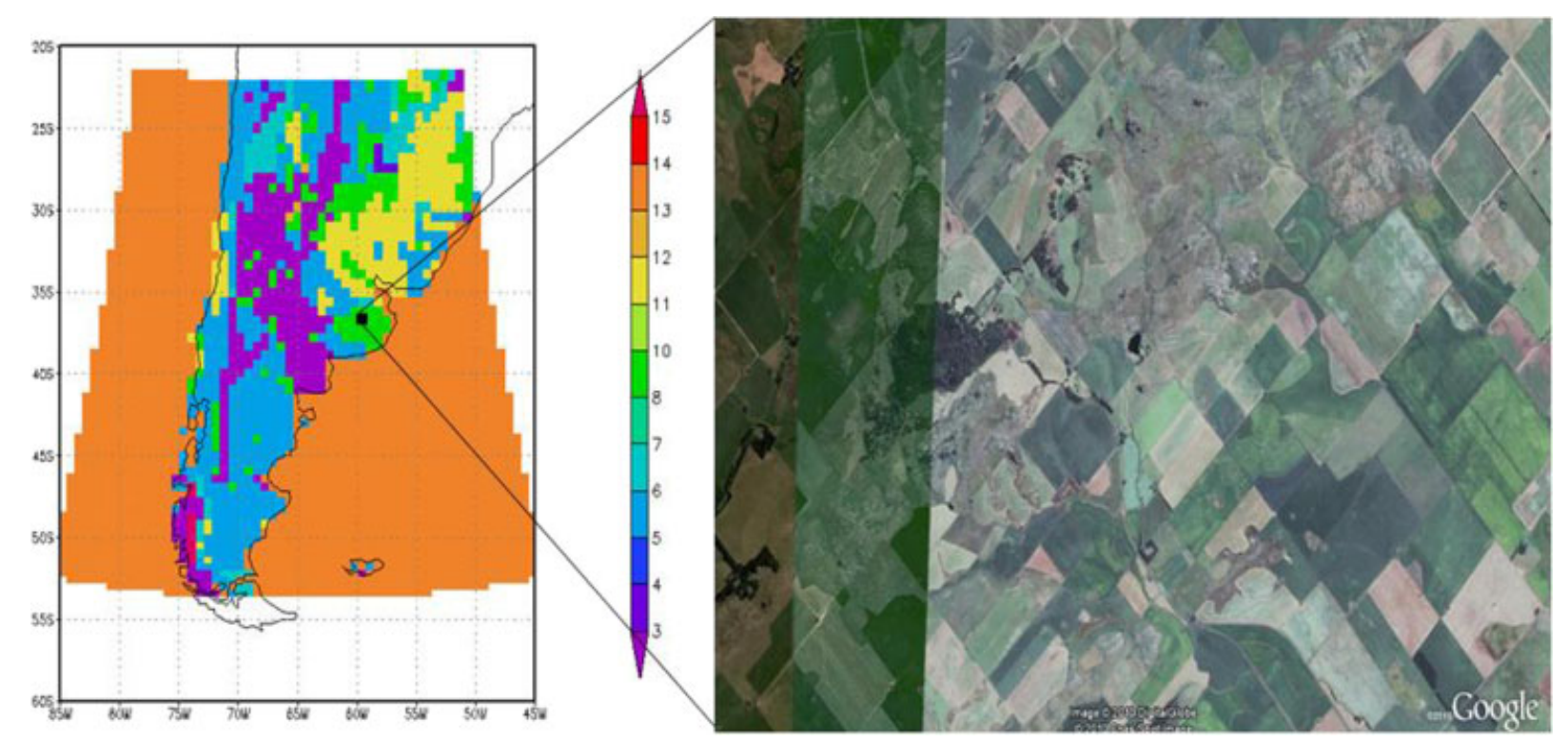

Figure I. Domain and soil types categories (shaded) used by the WRF model. 3, sand loam; 4, silt loam; 5, silt; 6, loam; 7, sandy clay loam; 8, silty clay loam; 9, clay loam; I0, sandy clay; II, silty clay; I2, clay; I3, organic material; I4, water; I5, others. The 'full square' indicates the model grid point employed in the present analysis. An amplified zone indicating the field campaign area is also included. 
Table I. Physical and biophysical parameters.

\begin{tabular}{|c|c|c|}
\hline & Model WRF-ARW & Estimated in field campaign \\
\hline Height above sea level & $218.15 \mathrm{~m}$ & $250 \mathrm{~m}^{\mathrm{a}}$ \\
\hline Dominant soil type & Clay loam & Clay silty loamb \\
\hline Field capacity & $0.38 \mathrm{~m}^{3} \mathrm{~m}^{-3}$ & $0.32 \mathrm{~m}^{3} \mathrm{~m}^{-3}$ \\
\hline Wilting point & $0.10 \mathrm{~m}^{3} \mathrm{~m}^{-3}$ & $0.2 \mathrm{~m}^{3} \mathrm{~m}^{-3}$ \\
\hline Dominant vegetation type & Cropland dryland and pastures & $\begin{array}{l}\text { Variable according to the season (crop and } \\
\text { pastures) }\end{array}$ \\
\hline Leaf area index & 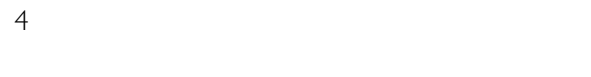 & $\begin{array}{l}\text { Variable according to the soil coverage and } \\
\text { state }(0.05-3.70)^{\mathrm{b}}\end{array}$ \\
\hline Albedo & $\begin{array}{l}\text { Variable according to the season (summer }=17 \% \text {, } \\
\text { winter }=20 \% \text { ) }\end{array}$ & $\begin{array}{l}\text { Variable according to the soil coverage, the soil } \\
\text { state and the season }(13-25 \%)^{c}\end{array}$ \\
\hline
\end{tabular}

a Instituto Geográfico Militar.

b Instituto Nacional de Tecnología Agropecuaria.

c Elías and Cusidó (1996).

\section{Results}

One important source of uncertainty in LSMs, particularly over the region of interest, is related to soil type (i.e. porosity, wilting point, hydraulic conductivity) and vegetation properties (i.e. albedo, LAI, vegetation fraction, roughness length), as they are largely unknown. Table I shows some of these parameters, as estimated during the field campaign and used by the WRF model. Most of the parameters differ substantially: for example, the LAI is fixed and higher in WRF. Also, crop rotation is not taken into account and the vegetation characteristics in the model vary according to summer or winter only. This impacts the evaporation of precipitation intercepted by the canopy and the transpiration via canopy and roots. Table I further illustrates that soil moisture cannot be strictly compared when soil/vegetation properties exhibit such disparity (Koster et al., 2009); for example, a difference in the wilting point constrains the extraction of water by the vegetation and consequently impacts the soil moisture content and evolution.

GLDAS and GDAS soil moisture mean absolute values at two depths (superficial $0-10 \mathrm{~cm}$ and subsuperficial 10-40 cm; Figure 2) are shown to document their behavior during the field campaign period. The superficial land-atmosphere exchanges have influence in the variability of the superficial soil moisture. The water storage decreases from the bottom throughout the surface as denoted by the larger mean values in the subsuperficial layer compared with the superficial ones.

In order to provide some meaningful comparison between models and observations, each data set value was normalized using its own dynamic range (maximum mean value minus minimum mean value). As a result of the normalization (shown in parenthesis in Figure 2), it was found that the observed values are around $30 \%$ different from that calculated by the models, showing that GLDAS is the model estimation closest to the observations.

Figure 3 illustrates normalized GDAS, GLDAS (at 12 UTC) and time-averaged WRF estimations (between 24 and $27 \mathrm{~h}$ simulation lead time) plotted day

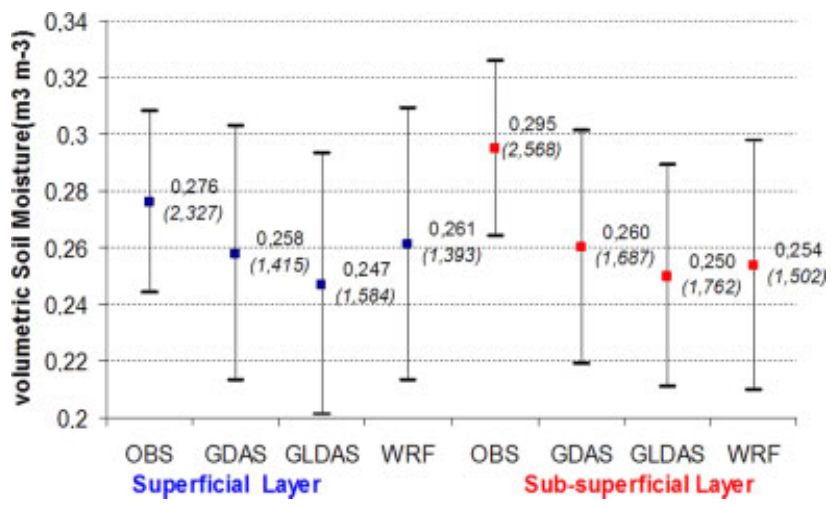

Figure 2. Mean soil moisture $\left(\mathrm{m}^{3} \mathrm{~m}^{-3}\right)$ observed and estimated by GDAS, GLDAS and WRF, with their standard deviation. Blue boxes correspond to the superficial layer and red boxes to the subsuperficial one. Normalized values are in parentheses.

by day. In general, WRF, GDAS and GLDAS estimations are lower than the observed values and only $40 \%$ of their values fall within the $99 \%$ confidence interval obtained from the observed variability. Relatively low values in model estimations (both at the superficial and subsuperficial layers) are partially associated with their higher temporal variability (recall that the actual amount is normalized by range). In general, soil moisture derived from 24 to $27 \mathrm{~h}$ WRF simulations is very close to or lies below the initialization value (i.e. GDAS), showing a slight model tendency to reduce soil moisture with forecast length and a higher temporal variability. This is consistent with a bias toward less precipitation reported in Ruiz et al. (2010).

The above-mentioned behaviour may be related, on one hand, with an erroneous representation of the surface characteristics, like the LAI: a higher LAI implies greater evapotranspiration and thus drier soils, especially at subsurface layers. Likewise, the WRF-ARW presents a lower wilting point than the observations, which would also lead to soil moisture reduction. On the other hand, there is another important source of uncertainty/error in soil moisture representation: that associated with precipitation. Analyzed data sets are forced with different precipitation values and therefore they are likely to exhibit important 

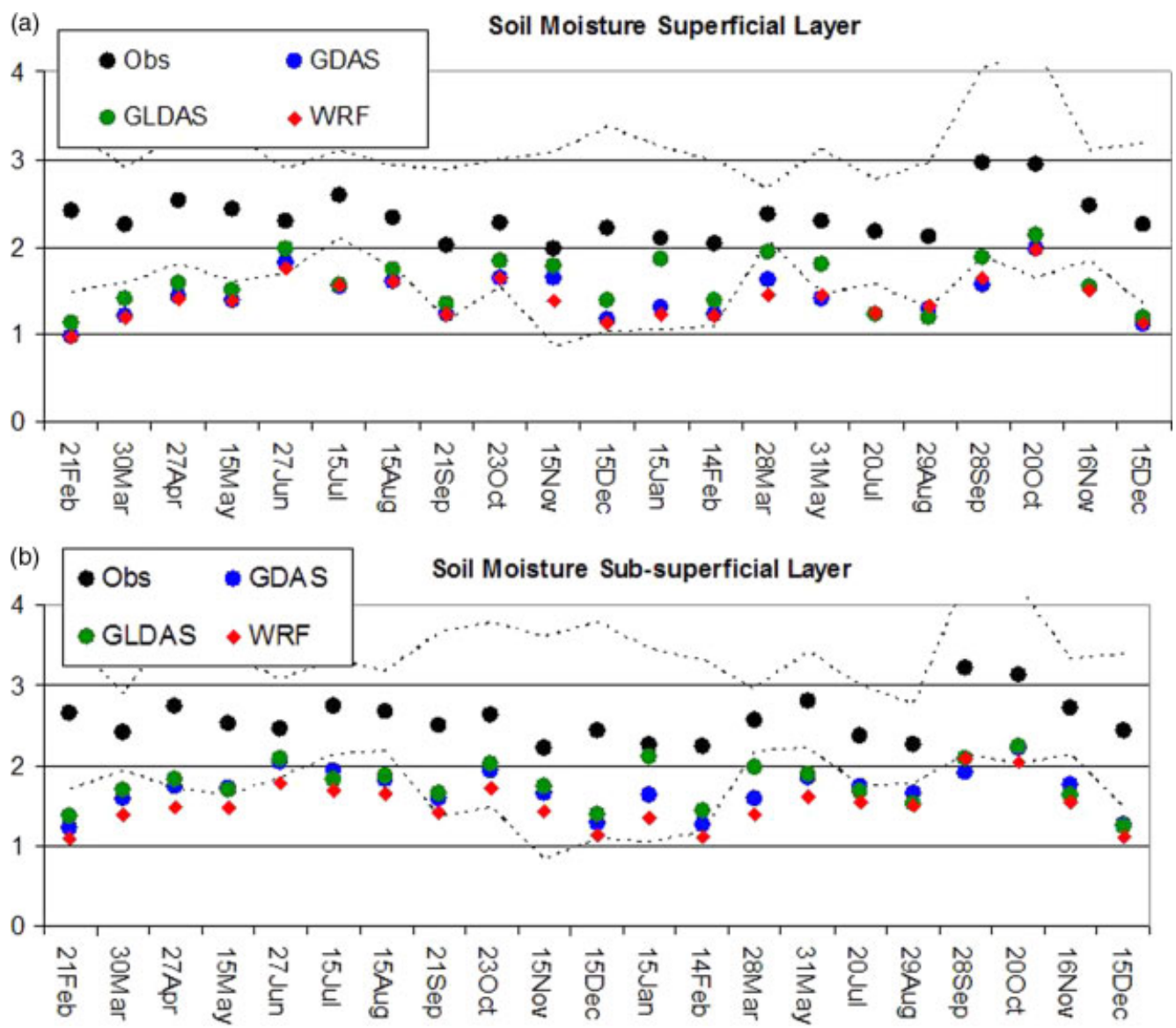

Figure 3. Normalized soil moisture for (a) the surface layer and (b) the subsuperficial layer. Each color refers to a different data set, as indicated in the box. Dotted lines show the calculated standard deviation from observations.
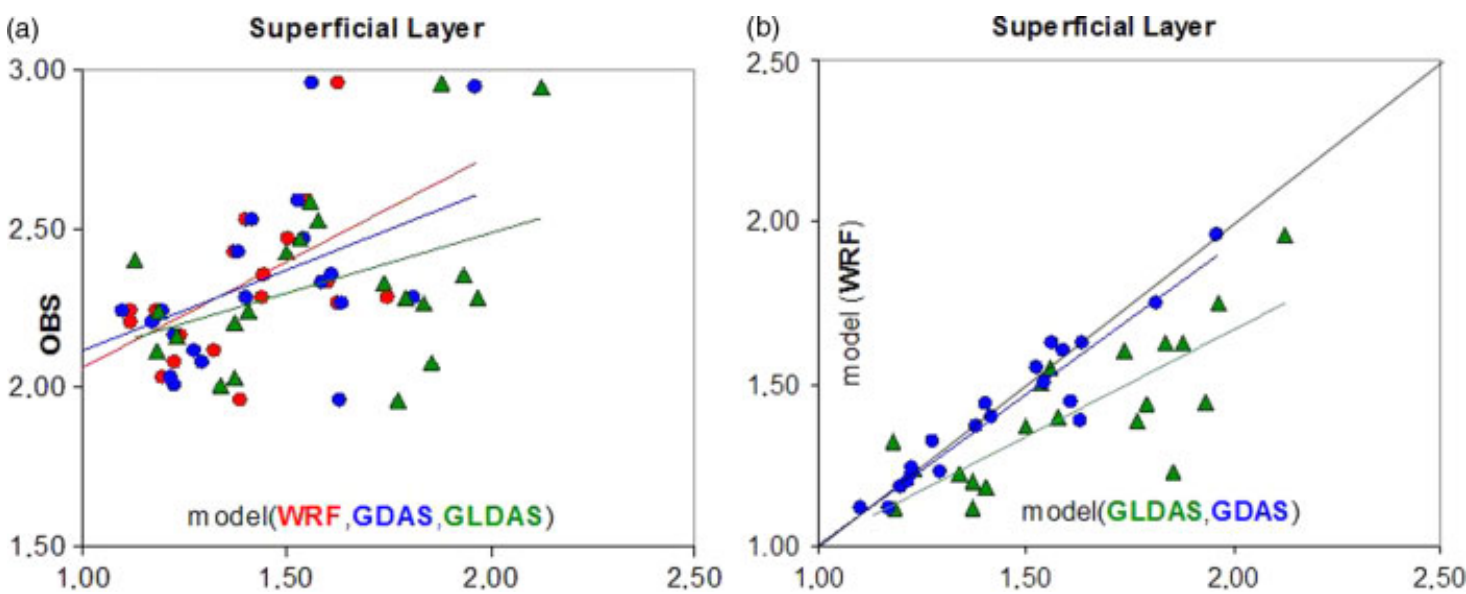

Figure 4. Comparison of normalized soil moisture at the superficial soil layer: (a) observed versus GLDAS (green), GDAS (blue) and WRF (red) models; and (b) WRF versus GDAS (blue) and GLDAS (green).

differences, as stated by Gottschalck et al. (2005). The fact that GLDAS seems to be closer to the observations suggests the importance of an accurate precipitation forcing.

Still, this figure exhibits a more significant problem regarding the representativeness of model-derived soil moisture: according to Koster et al. (2009), LSMs soil moisture indicators usually have useful information about variability, but, apparently, this does not apply to our case. Figure 4(a) denotes a poor correlation among the observations and model-derived data. On the other hand, when only the latter are compared (Figure 4(b)), the correlation is high. This response is supported by the fact that these data sets share the same LSM, so it can be inferred that the differences are related both to the precipitation forcing (i.e. GLDAS employs CMAP data while GDAS and WRF-ARW employ their own precipitation) and, to a lesser extent, to the surface configuration, which may have minor differences among NOAH model settings. GDAS and 


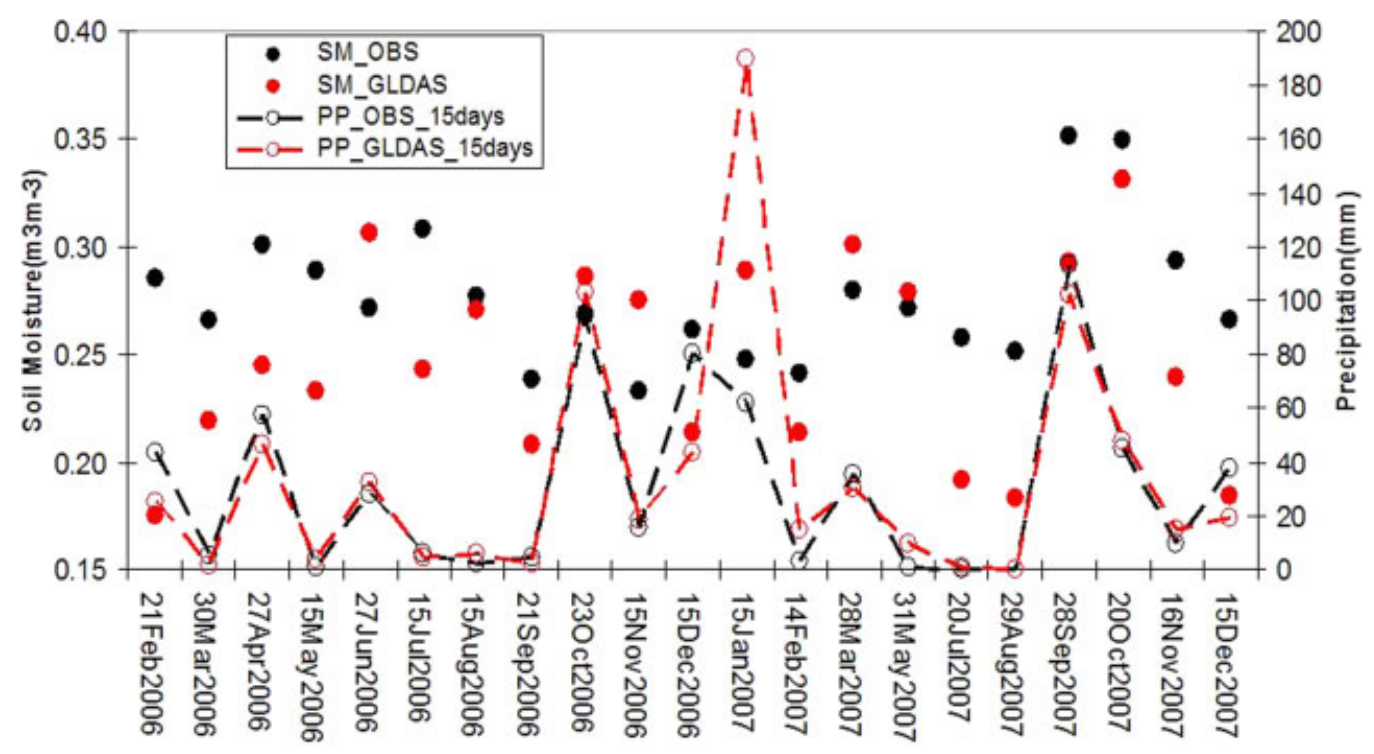

Figure 5. Observed and GLDAS soil moisture $\left(\mathrm{m}^{3} \mathrm{~m}^{-3}\right)$ (black and red dots, respectively) and accumulated precipitation (mm) (observed, black dashed and GLDAS, red dashed). Accumulation period corresponds to 15 days before measurement date (indicated in the abscissa).

WRF seem to be more correlated, which is probably due to the use of GDAS for initializing and providing the boundary conditions.

In order to provide extra information on how precipitation modulates soil moisture during this field campaign, a 15-day accumulated precipitation (corresponding to 15 days previous to the sampling dates) was obtained from GLDAS and compared against the observational data from the National Argentinean National Weather Service surface station, located at $36^{\circ} 50^{\prime} \mathrm{S}$ and $59^{\circ} 50^{\prime} \mathrm{W}$. The following analysis focuses on the superficial soil moisture.

To obtain values representative of soil states, measurements were taken during days without precipitation (Salgado, 2009). Accordingly, to analyze the role of precipitation on soil moisture variability we consider all the precipitation events in a certain time period prior to the date of the observations. Taking into consideration Dirmeyer et al.'s (2009) results, documenting the root-zone soil moisture memory over South America, we consider that 15 days was suitable to accomplish our objective.

Figure 5 shows that GLDAS-accumulated precipitation (using the grid point nearest to the observation) compares well with observed values, except for the period between 15 December 2006 and 15 January 2007. As expected, the soil moisture variability reflects precipitation variability. The relation between the soil moisture and precipitation is more evident for GLDAS than for the observations, probably indicating that the model is strongly tied to precipitation. However, there appears some exceptions, when a decrease of precipitation is not followed by a decrease in soil moisture. For these situations, we explore the precipitation series and found that a strong precipitation event occurred between 20 or 30 days before the sampling date. This may suggest that soil moisture memory could be larger than 15 days. Conversely, when an increase of precipitation is not accompanied by an increase in soil moisture, as for 15 December 2006 and 27 June 2007, it may suggest that precipitation amounts are not enough to reverse soil moisture trend, at least within the period encompassed by each measurement. Agricultural activities may also modulate this variability as shown by Hébrard et al. (2006). Their management and agricultural practices (planting, tillage, crop type, chemical controls, etc.) strongly influence the dynamics of superficial water that may result in changes of the surface soil hydraulic conditions. Even the direction of the furrows of the fields determines the transfer of water to the basin outlet.

\section{Conclusions}

This work examines soil moisture derived from available global models which are widely used for assessing land-atmosphere feedback mechanisms (like GLDAS$\mathrm{NOAH}$ ) and/or initializing Numerical Weather Predictions models, as GDAS data set. Also, we included the WRF short-range simulations, as a way to identify how soil moisture is represented during the initial stages of the simulation.

To perform this analysis, we employed a unique soil moisture data set from a measurement campaign carried out over an area in the Buenos Aires province. This region, as well as the rest of the country lacks enough soil moisture measurements and the uniqueness of this data set guarantees the distinctiveness of the analysis performed.

Soil moisture is an LSM-derived variable and it is acknowledged that it is a physical quantity that cannot be compared directly with on-site measurements 
(Koster et al., 2009). For this reason, we normalized this variable using corresponding dynamic range extremes. The results show large differences between LSM and field campaign values, not evident when absolute values are compared. Model-derived values were systematically below the observed ones.

Temporal variability is not well reproduced by any of the derived soil moisture data sets, and this problem does not seem to be explained by a failure in the representation of precipitation, which in general denotes reasonable agreement between observations and forcing data used to run soil models (at least this is the case for GLDAS). Our results suggest that important efforts should be carried out in order to better represent regional soil moisture variability including the analysis of remote sensing information. Given the lack of in situ data, passive microwave remote sensing is one of the most important techniques for soil moisture retrieval which could aid in a better assessment of the complexity of soil moisture behavior in the superficial layers and its interactions with the atmosphere.

\section{Acknowledgements}

This study has been supported by the following projects: UBACyT X204, PIDDeF 41/10, PIDDeF 47/10 and CONICET PIP 112-200801-00399. The research leading to these results has received partial funding from the European Community's Seventh Framework Programme (FP7/2007-2013) under Grant Agreement 212492 (CLARIS LPB; a Europe-South America Network for Climate Change Assessment and Impact Studies in La Plata Basin). The authors wish to thank the contribution from the anonymous reviewers that substantially helped to improve the manuscript.

\section{References}

Anderson JR, Hardy EE, Roach JT, Witmer RE. 1976. A land use and land cover classification system for use with remote sensor data, US Geological Survey Professional Paper 964. Government Printing Office: Washington; 41.

Betts A. 2009. Land-surface-atmosphere coupling in observations and models. Journal of Advances in Modeling Earth Systems 1: Art no. 4, 18. DOI: 10.3894/JAMES.2009.1.4.

Chen F, Dudia J. 2001. Coupling an advanced land-surface/hydrology model with the Penn State/NCAR MM5 modeling system. Part I: model description and implementation. Monthly Weather Review 129: 569-583.

Collini EA, Berbery EH, Barros V. 2008. How does soil moisture influence the early stages of the south American monsoon? Journal of Climate 21: 195-213.

Dirmeyer PA, Schlosser CA, Brubaker KL. 2009. Precipitation, recycling, and land memory: an integrated analysis. Journal of Hydrometeorology 10: 278-288.

Dudhia J. 1989. Numerical study of convection observed during the winter monsoon experiment using a mesoscale two-dimensional model. Journal of the Atmospheric Sciences 46: 3077-3107.

Gevaerd R, Freitas SR. 2006a. Estimativa operacional da umidade do solo para iniciação de modelos de previsão numérica da atmosfera.
Parte I: descrição da metodologia e validação. Revista Brasileira de Meteorologia 21: 59-73.

Gevaerd R, Freitas SR, Longo M, Moreira DS, Faus da Silva Dias MA, Leite da Silva Dias PL. 2006b. Estimativa operacional da umidade do solo para iniciação de modelos de previsão numérica da atmosfera. Parte II: impacto da umidade do solo e da parametrização de cumulus na simulação de uma linha seca. Revista Brasileira de Meteorología 21: 74-88.

Gottschalk J, Meng J, Rodell M, Houser P. 2005. Analysis of multiple precipitation products and preliminary assessment of their impact on Global Land Assimilation System (GLDAS) land surface states. Journal of Hydrometeorology 6(5): 573-598.

Grimm A, Pal JS, Giorgi F. 2007. Connection between spring conditions and peak summer monsoon rainfall in south america: role of soil moisture, surface temperature, and topography in Eastern Brazil. Journal of Climate 20: 5929-5945.

Hébrard O, Voltz M, Andrieux P, Moussa R. 2006. Spatio-temporal distribution of soil surface moisture in a heterogeneously farmed Mediterranean catchment. Journal of Hydrology 329(1-2): 110-121.

Hong SY, Lim JOJ. 2006. The WRF single-moment 6-class microphysics scheme (WSM6). Journal of the Korean Meteorological Society 42: 129-151.

Hong SY, Pan H. 1996. Non-local boundary layer vertical diffusion in a medium-range forecast model. Monthly Weather Review 10: $2322-2339$.

Kain JS. 2004. The Kain-Fritsch convective parameterization: an update. Journal of Applied Meteorology 43: 170-181.

Koster RD, Zhichang G, Rongqian Y, Dirmeyer P, Kenneth M, Puma M. 2009. On the nature of soil moisture in land surface models. Journal of Climate 22: 4322-4335.

Mlawer EJ, Taubman SJ, Brown PD, Iacono MJ, Clough SA. 1997. Radiative transfer for inhomogeneous atmosphere: RRTM, a validated correlated-k model for the long-wave. Journal of Geophysical Research 102: 16663-16682.

Rodell M, Houser PR, Jambor U, Gottschalck J, Mitchell K, Meng CJ, Arsenault K, Cosgrove B, Radakovich J, Bosilovich M, Entin JK, Walker JP, Lohmann D, Toll D. 2004. The global land data assimilation system. Bulletin of the American Meteorological Society 85: $381-394$.

Ruiz JJ, Saulo C, Nogués-Paegle J. 2010. WRF model sensitivity to choice of parameterization over south America: validation against surface variables. Monthly Weather Review 138: 3342-3355. DOI: 10.1175/2010MWR3358.1.

Salgado H. 2009. Estimación de la Variabilidad de la Humedad del Suelo en Base a Modelización Hidrológica y Teledetección en la Cuenca del Arroyo Pablo Acosta, Provincia de Buenos Aires, Argentina. PhD Dissertation, Universidad de Buenos Aires EPG FAUBA, 118 pp.

Saulo C, Cardazzo S, Ruiz JJ, Campetella C, Rolla A. 2008. Experimental forecast system at the Research Center for the Sea and the Atmosphere. Meteorologica 33: 83-97.

Saulo C, Ferreira L, Nogués-Paegle J, Seluchi M, Ruiz JJ. 2010. Land-atmosphere interactions during a Northwestern Argentina Low event. Monthly Weather Review 138: 2481-2498. DOI: 10.1175/2010MWR3227.1.

Skamarock WC, Klemp JB, Dudhia J, Gill DO, Barker DM, Wang W, Powers JG. 2005. A Description of the Advanced Research WRF Version 2, NCAR Technical Notes-468+STR.

Stensrud. 2007. Parameterization Schemes: Keys To Understanding Numerical Weather Prediction Models Cambridge University Press Cambridge.

Viterbo P. 2001. Meteorological Training Course Lecture Series. ECMWF: Reading, England.

Xue Y, De Sales F, Li WP, Mechoso CR, Nobre CA, Juang HM. 2006. Role of land surface processes in south American monsoon development. Journal of Climate 19: 741-762. 